\title{
Communications, Navigation and Surveillance for Improved Oceanic Air Traffic Operations
}

\author{
Robert J. Kerczewski, Israel Greenfeld, Bryan W. Welch \\ NASA Glenn Research Center \\ Cleveland, Ohio, USA \\ +1 216433 3434, rkerczewski@nasa.gov \\ +1 216433 5305, Israel.Greenfeld@grc.nasa.gov \\ +1 216433 3390, Bryan.W.Welch@nasa.gov
}

\begin{abstract}
Air traffic management around the world is implemented using ground-based communications, navigation and surveillance systems. For obvious reasons, such systems are not available in oceanic airspace, nor are they available in remote land regions. In general, aircraft operating in these regions maintain safe separations by relying on procedural separation methods. Such methods require separations of 50 nautical miles $(\mathrm{nm})$ or more to be maintained. As air traffic across the oceans increases, the procedural separations are leading to increased inefficiencies in oceanic and remote operations. These inefficiencies result from schedule delays, inability to fly preferred routes (for best wind advantages), and the inability to use the most efficient altitudes, leading to higher fuel burn rates. New methods of operating in oceanic and remote airspace are needed, and indeed they are being developed and implemented, but they depend on an improved communications, navigation and surveillance (CNS) systems, which of necessity must be primarily supplied by satellite-based systems. This paper summarizes current and future air traffic management operations, the CNS requirements for future operations and satellite-based systems which have the potential for fulfilling these requirements, and what is needed to bring such system to implementation. ${ }^{12}$
\end{abstract}

\section{TABLE OF CONTENTS}

\section{INTRODUCTION \\ 2. OCeanic Air Traffic Management OPERATIONS \\ 3. CURRENT OCEANIC CNS \\ 4. CNS REQUIREMENTS FOR IMPROVED OCEANIC OPERATIONS \\ 5. SATEllite-BASEd SySTEMS FOR OCEANIC COMMUNICATIONS AND SURVEILLANCE \\ 6. SUMMARY \\ 7. REFERENCES}

\footnotetext{
${ }^{1}$ U.S. Government work not protected by U.S. copyright.

${ }^{2}$ IEEEAC paper \#1580, Final Version, Updated January 1, 2005
}

\section{INTRODUCTION}

International air travel continues to increase at a rapid pace. The US Federal Aviation Administration (FAA) forecasts continuing growth rates of $3.9 \%$ or more through 2030 for flights to and from the United States[1]. Traffic crossing oceanic airspace in other regions of the world may grow even more rapidly. Yet oceanic operations cannot keep pace with this demand while employing communications technologies first used over 50 years ago, namely voice communications in the high frequency (HF) band, relayed by HF operators to and from air traffic control facilities. This fundamental deficiency greatly constrains the ability to improve the efficiency of oceanic operations, often requiring aircraft to maintain separation distances of 50-100 $\mathrm{nm}$, while aircraft operating in domestic airspace with ground-based VHF communications and full radar surveillance coverage routinely operate at $5 \mathrm{~nm}$ spacing.

In June, 2004, the Working Group on Oceanic and Sparse Area Communications, of the FAA Research, Engineering, and Development Advisory Committee (REDAC) Air Traffic Services Subcommittee [2] reported: "The efficiency and capacity of aircraft operations in oceanic and sparse area airspace are limited by a number of factors, one of which is the lack of a rapid, reliable means of communication between aircraft and control facilities. This results in significant economic penalties to aircraft operators by forcing many flights to use non-optimum routes, a situation that will worsen as traffic levels increase in the future." The working group recommended the FAA "initiate an activity to develop standards for an oceanic communication system that can meet the needs of advanced oceanic operations. The system should initially meet the requirements for $30 / 30$ separation (30 miles lateral, 30 miles longitudinal), but should have the potential for closer spacing when and if indicated by demand. The standards should be realizable by a system that is economical to install and operate for a broad class of aircraft."

Lack of surveillance information and inadequate communications capabilities result in large uncertainties in aircraft position, leading to required large aircraft separations in oceanic airspace. Access to the most efficient routes is greatly reduced, and the ability to deviate from 
Table 1 - Example of Economic Penalties due to Inefficient Oceanic Routes [3]

\begin{tabular}{|l|c|c|c|}
\hline & $\begin{array}{c}\text { Most Fuel } \\
\text { Etificient Route* }\end{array}$ & $\begin{array}{c}\text { Fuel Efficient } \\
\text { Route Shifted } \\
100 \mathrm{NM}\end{array}$ & Difference \\
\hline Distance & $5,770.7 \mathrm{NM}$ & $5,778.5 \mathrm{NM}$ & $7.8 \mathrm{NM}$ \\
\hline A verage Heachinds & $52 \mathrm{knots}$ & $66 \mathrm{knots}$ & $14 \mathrm{knots}$ \\
\hline Time & 772 minutes & 799 minutes & 27 minutes \\
\hline Pounds of Fuel & $330,146 \mathrm{lbs}$. & $338,071 \mathrm{lbs}$. & $7,925 \mathrm{lbs}$. \\
\hline $\begin{array}{l}\text { Callons of Fuel } \\
\text { (1 gal. = 6.78 lbs.) }\end{array}$ & 48,694 gals. & 49,863 gals. & 1,169 gals. \\
\hline $\begin{array}{l}\text { Cost of Fuel (9) \$1.20/gal } \\
\text { (Feb 2003 ATA testimony) }\end{array}$ & $\$ 58,433$ & $\$ 59,836$ & $\$ 1,403$ \\
\hline
\end{tabular}

* Using forecast winds and temps, fuel efficient tracks are built between city pairs

predefined flight plans to obtain better operating altitudes and avoid weather problems is significantly constrained.

An example of the economic penalties imposed on aircraft operators flying oceanic routes by the inability to obtain the most efficient routes can be seen in Table 1, developed by the U.S. Federal Aviation Administration (FAA) [3]. For a typical route, shifted $100 \mathrm{~nm}$ from the most fuel efficient routes, an additional 7,925 pounds of fuel, and 27 minutes of additional flight time are required. When these types of penalties are multiplied by the hundreds of daily transoceanic flights, the overall additional fuel costs to airlines, as well as costs incurred for schedule delays, is significant.

The combination of poor communications coverage and non-existent surveillance can be overcome using satellite communications services. Modern digital satellite communications can provide a direct communications link between pilots and air traffic controllers, and can also provide a means for constant position reporting based on accurate navigational data based on satellite navigation techniques.

Air traffic service (ATS) organizations around the world charged with oceanic responsibilities are now deploying new automation systems that can make use of such a digitally based communications and position reporting system. Many aircraft are equipped with satellite communications systems capable of implementing the Future Air Navigation System (FANS) standards. FANS is an international standard defining digital communications and position reporting for oceanic and remote area operations based on satellite communications and navigation[4]. FANS equipped aircraft can operate effectively with the new automation systems, ultimately enabling more efficient oceanic operations with reduced aircraft separation. However, it is necessary that a high percentage of aircraft be equipped in order to obtain substantial efficiency gains.

The generally high cost of installing and operating satellite communications equipment for FANS capabilities has been a significant factor in the decision of airlines to equip with FANS. Current aeronautical safety communications services via satellite are provided through Inmarsat satellites operating at L-band frequencies. However, a number of possible new systems are available now or in the near future that could also provide the satellite communications links for FANS services, at lower cost. These systems may provide the business case leading to full equipage of the oceanic fleet and enabling the hoped-for oceanic operational efficiency gains to be realized. But first, technological, safety/certification, aviation standards, and perhaps international frequency allocation issues must be resolved.

\section{Oceanic Air Traffic Management OPERATIONS}

Oceanic air traffic is managed by oceanic air traffic control (ATC) centers operated by many different air traffic service providers (ATSP) around the world. Figure 1 depicts oceanic flight information regions (FIR) around the world as designated by the International Civil Aviation Organization (ICAO). Numerous ATSPs control the various FIRs. The FAA actually manages most of the world's oceanic airspace, including most of the Pacific Ocean. 


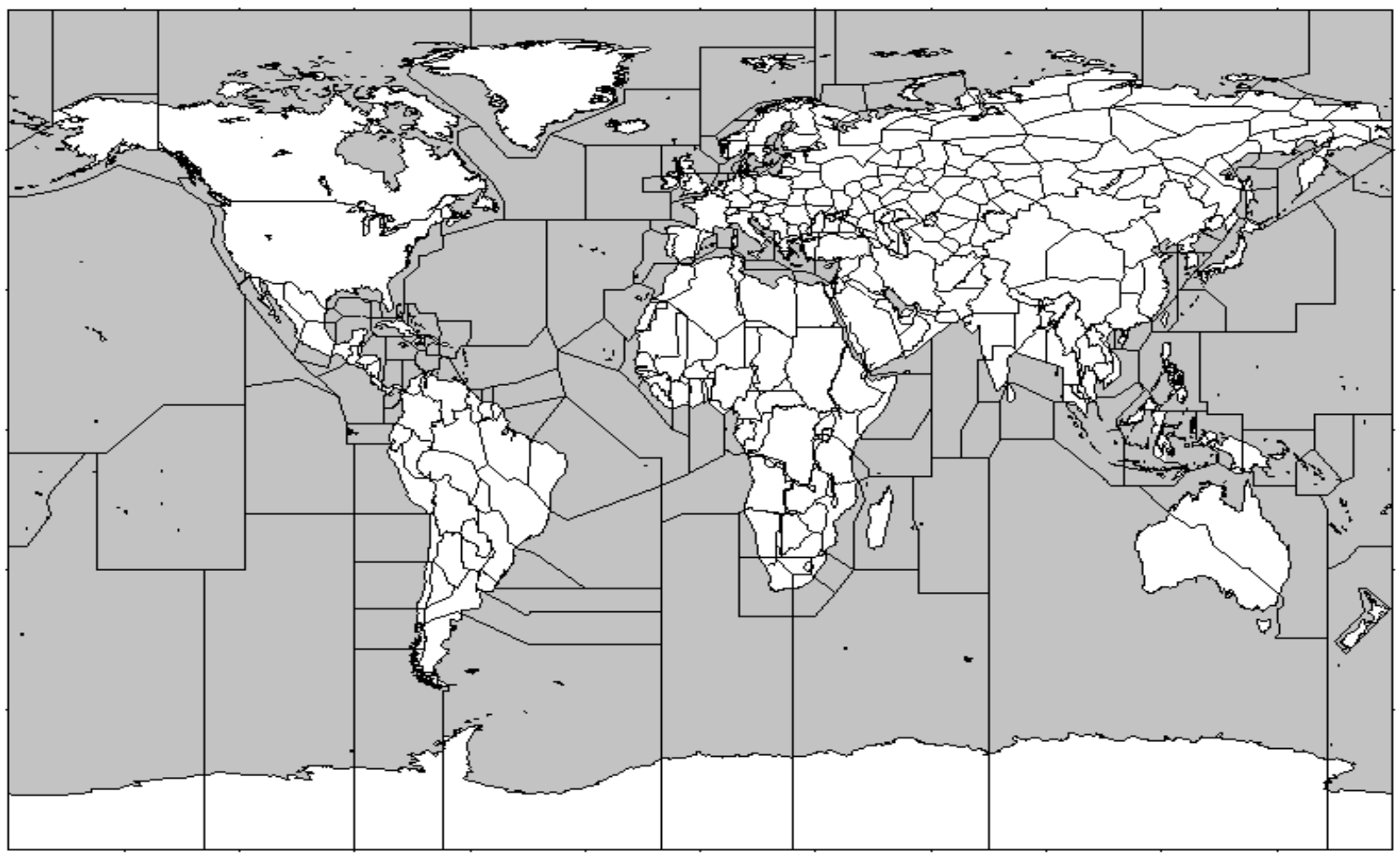

Figure 1 - Oceanic Flight Information Regions

The majority of all communications between aircraft and ATC in general is performed using VHF line-of-sight radio links. It is cost-prohibitive to locate VHF stations in the ocean, hence VHF line-of-sight communications can only reach about $200 \mathrm{~nm}$ from land, leaving most oceanic areas without VHF communications. Similarly, surveillance of aircraft is primarily accomplished through ground-based radars, which again can extend only a few hundred $\mathrm{nm}$ from land. Finally, for navigation, the typical ground-based navigation aids used in continental regions are unavailable in oceanic airspace. For these reasons, the separation of aircraft in oceanic regions is more than 10 times that required over continental regions where land-based CNS systems are available.

In the current oceanic ATM environment, pilots send position reports approximately every hour, or every $10^{\circ}$ of longitude. These position reports represent the only surveillance capabilities available to air traffic controllers in oceanic airspace. The communication method used is high frequency (HF) analog voice communications. These communications rely on the atmospheric refractive qualities of radiofrequency electromagnetic waves in the HF band $(2100-28000 \mathrm{kHz})$ that enable such radio transmissions to travel great distances, well beyond line-of-sight. However, HF voice is of poor quality and requires retuning to find a particular frequency that is working well under current conditions. Voice messages are routed through "call centers" operated by service providers, with messages relayed to the air traffic controller. Thus, it may take several minutes or more for position reports to reach the controller, resulting in a very large uncertainty in knowledge of aircraft location, requiring large margins in the separation of aircraft to ensure safety. An additional consequence of the poor communications and position uncertainty is that the granting of aircraft requests for altitude or other course changes are infrequent.

The result is a mix of procedures depending on the particular oceanic and the capabilities of the particular air craft. Some ATSPs have implemented a portion of the ICAO procedures that alleviate congestion but others have not. These procedures provide include:

- $50 \mathrm{~nm}$ longitudinal/lateral separations and eventually $30 \mathrm{~nm}$;

- Reduced Vertical Separation Minimum (RSVM) from 2000 to 1000 feet vertical;

- In-Trail Climb/In-Trail Descent (ITC/ITD);

- Dynamic Air Route Planning (DARP).

These procedures will enable improved efficiency of oceanic ATM by allowing additional oceanic routes, closer spacing of aircraft so that more aircraft can use a particular route, availability of more efficient altitudes, and greater ease of mid-flight changes in routes and altitudes. However, these procedures require improvements in CNS capabilities of aircraft as well as improved automation of ATC centers. 


\section{Emerging/Future Oceanic Operations}

Providers of oceanic air traffic services (ATS) are now deploying new oceanic ATS automation systems[2]. These include Australia (TAAATS); New Zealand (OCS); Fiji (EASY); Canada (GAATS); UK (GAATS); and US (ATOP).

These systems rely upon automatic position reports, known as Automatic Dependent Surveillance (ADS) and digital messaging between the controller and pilot, known as Controller-Pilot Data Link Communications (CPDLC) as FANS satellite data link applications. ATOP is described further below. These systems will enable safe reduction of spacing to at least $30 / 30 \mathrm{~nm}$, but require aircraft to be properly equipped. The first full operations for $30 / 30 \mathrm{~nm}$ separation will occur in the South Pacific, on flights between the United States and Australia, in 2005 when ATOP is fully operational. The fleet of aircraft that fly these routes are all currently fully FANS equipped via Inmarsat satellite communications links and compatible aeronautical earth stations.

Advanced Technologies and Oceanic Procedures (ATOP) is an example of the new oceanic ATS automation systems now being deployed. ATOP is an FAA program that provides automated processing of FANS-based messages and other automation features designed to significantly improve oceanic air traffic operations. ATOP includes flight data processing (FDP) and surveillance data processing (SDP). SDP will integrate primary \& secondary radar data, Automatic Dependent Surveillance (ADS) data (both -A or Addressable and $-\mathrm{B}$ or Broadcast), Controller Pilot Data Link Communications (CPDLC) position reports, and the relayed HF voice reports of current practice. ATOP is also designed to conduct wind modeling and to process weather messages, to generate 4-D trajectory models, and provide controller tools that enhance safety by automatically calculating trajectory parameters and pointing out potential air conflicts. Aircraft situational awareness will be enhanced and change requests and clearances handled more efficiently and safely.

The far-term vision of oceanic operations was recently proposed by RTCA[5]. It considers expanded capabilities available to all aircraft and in all airspace resulting in userpreferred routes and increased airspace capacity through further reductions in separation minima. Automation and decision support systems provide the position of all aircraft to controllers. Seamless communications services and higher data rate position reporting for surveillance will be achieved primarily through satellite communications technology. This vision demonstrates the need for improved oceanic communications and surveillance capabilities to support greatly improved oceanic operations for the future.

\section{Current Oceanic CNS}

As described previously, the majority of trans-oceanic aircraft use HF voice, with its known deficiencies and latencies, for position reporting and voice communications to oceanic ATC facilities. Controller-to-pilot voice communications are not direct, but are handled through third party call routing centers. Satellite voice, through Inmarsat satellites in the L-band around $1.6 \mathrm{GHz}$, using Inmarsat Aeronautical terminals, provides better performance, but is also routed through third party call centers. Because it is relatively costly, it is not heavily used.

The gradual emergence of FANS has enabled the use of satellite communications for direct digital communications between aircraft and oceanic ATC. FANS, described further below, can provide the communications capability that new ATSP automation systems require. However, equipage with Inmarsat-compatible aeronautical terminals for FANS has been slow due to both the lack of complete deployment of new ATC automation and the relatively high cost of avionics and messaging service.

\section{FANS}

The Future Air Navigation System (FANS) exists in two versions known as FANS 1/A. The "1" designates the system developed by Boeing while " $A$ " refers to the system developed by Airbus. Each equips their aircraft with their system but design the systems to have global compatibility with the basic FANS components. The components are ADS and CPDLC with support from the GPS system and communications over satellite, specifically Inmarsat.

FANS enables automatic digital position reports, as well as digital messaging, directly between the aircraft and the controller via the ATOP automation system. In oceanic and remote regions, FANS can be operated over Inmarsat Lband satellite communication links.

A serious issue in obtaining the many operational efficiency benefits in oceanic and remote regions that can be derived from the combination of FANS-equipped aircraft and oceanic ATM automation systems such as ATOP is that a significant percentage of aircraft must be equipped before significant benefits can be derived. The cost of equipping with FANS-Inmarsat avionics is significant, and the extremely thin profit margins at which airlines operate make it very challenging to obtain a sufficient cost-benefit ratio. It's important to note that many airlines operate their long haul aircraft in many different regions, so to equip for FANS services for oceanic flight may require equipping all long haul aircraft in the fleet rather than just enough for several daily oceanic flights.

As mentioned previously, surveillance capabilities in oceanic airspace, beyond line-of-sight of land areas, are currently based upon pilot position reports. Pilots report 
their positions based upon data derived from aircraft navigational systems. While improved navigational capabilities of aircraft will result in more accurate surveillance through more accurate position reports, the limitations induced by $\mathrm{HF}$ voice in position reporting, especially the long latency, render major inaccuracies in knowledge of aircraft position by controllers.

Navigation in oceanic regions can now make use of global satellite positioning systems, such as GPS. GPS, combined with the aircraft's on-broad inertial navigation systems, can produce greatly improved navigational accuracies necessary for reduced separation. The introduction of RVSM in oceanic regions has required aircraft to equip with improved navigational systems in order to be allowed to make use of RVSM procedures, and retrofitting older aircraft with improved navigation systems is proceeding, since the economic benefits of RVSM enable costs of equipping to be recovered by the aircraft operators.

\section{CNS REQUIREMENTS FOR IMPROVED OCEANIC OPERATIONS}

In the long term, continued traffic growth over oceanic and remote regions will necessitate further reductions in aircraft spacing to maintain and improve operational efficiencies. Reducing spacing from $30 / 30 \mathrm{~nm}$ to $20 / 20$, or eventually $10 / 10 \mathrm{~nm}$ will require significantly higher communications. Table 2 shows the calculated requirements for communications, navigation and surveillance system performance as derived by Boeing and reported in [6].

As Table 2 shows, the communications requirements and navigation requirements increase as separation decreases, but not in a major way, other than the requirement for direct voice communications between pilot and controller at 10/10 separation. However, the requirements for surveillance messaging increase substantially and non-linearly, as separation decreases from $30 / 30$ to $20 / 20$ to $10 / 10$. The number of position reports required per hour increase from 4.3 for $30 / 30$ separation to 240 for $10 / 10$ separation. This creates a significant surveillance/communications link traffic load with a corresponding messaging cost increase.
However, given the expectation of constant trans-oceanic traffic increases for the foreseeable future, new communications/surveillance systems introduced into aviation must take the eventual need for $20 / 20$ and $10 / 10 \mathrm{~nm}$ separation into account in order for systems with long lifetimes to be developed and accepted by the oceanic airspace users. In other words, users will prefer to equip with systems that are expected to be useful for many years. However, such systems must provide a rapid return on investment upon initial deployment.

An important secondary desire for oceanic communications results from the value of improved weather information. Airlines and other airspace system users could achieve significant operational benefits if information about such weather phenomena as convection, turbulence, and wind forecasts were well known, with accurate and up-to-date information. Slight flight adjustments made well in advance of approach weather, rather than last-minute maneuvers, can result in lower fuel consumption and better schedule management. Volcanic ash clouds can cause severe, dangerous and expensive damage to jet engines. Volcanic events can occur suddenly and create hazards within hours. Currently very little weather information is forwarded to aircraft in oceanic flight. Most weather data is obtained in the pre-flight stage. Provision of weather information via oceanic satellite links may prove very cost effective and should be considered for future systems.

\section{SATEllite-BASEd SySTEMS FOR OCEANIC COMMUNICATIONS AND SURVEILLANCE}

Given continuing advances in satellite communications capabilities, and the introduction of new services, other options for providing oceanic communications and surveillance can be explored that would provide a greater incentive for airlines to equip, and thereby obtain a level of aircraft equipage great enough to generate the projected efficiency benefits, after which the cost/benefit case is much easier to make.

Existing satellite communications for oceanic air traffic

\section{Table 2 - Communications, Navigation and Surveillance Requirements for Reduced Oceanic Separation[5]}

\begin{tabular}{|c|c|c|c|}
\hline $\begin{array}{c}\text { Separation } \\
\text { (Lateral/Longitudinal) }\end{array}$ & $\begin{array}{c}\text { Communication and } \\
\text { Controller Intervention Time }\end{array}$ & $\begin{array}{c}\text { Navigation } \\
\text { Performance }\end{array}$ & $\begin{array}{c}\text { Surveillance } \\
\text { (Update/Latency) }\end{array}$ \\
\hline $30 \mathrm{~nm} / 30 \mathrm{~nm}$ & 6 minutes & $\mathrm{RNP}-4$ & $14 \mathrm{~min} . / \mathrm{min}$. (ADS) \\
\hline $20 \mathrm{~nm} / \mathbf{2 0 n m}$ & 6 minutes & RNP-4 & $1 \mathrm{~min} . / 15 \mathrm{sec}$. (ADS) \\
\hline $10 \mathrm{~nm} / \mathbf{1 0 n m}$ & 3 minutes Direct Voice & $\mathrm{RNP}-2$ & $15 \mathrm{sec} . / 3 \mathrm{sec}$. (ADS) \\
\hline
\end{tabular}


management makes use of Inmarsat 3 satellites. Many aircraft are equipped with Inmarsat-compatible aeronautical earth stations (AES). An AES may provide passenger or crew telephone service. A subset of aircraft with Inmarsat connectivity are FANS-enabled, which requires both the AES and aircraft avionics that interfaces with an aircraft's flight management computer to create and interpret FANS messages. Although aircraft equipped in this manner are compatible with new oceanic ATC automation systems, a primary driver inhibiting a large percentage of aircraft equipage is the cost of both the avionics and the messaging service. The development of lower cost oceanic satellite communications for ATC would provide accelerated benefits by creating a more favorable cost-benefit situation.

To qualify as a communications link for CNS, a satellite system must comply with the Air Mobile Satellite System (AMSS) requirements in terms of frequency allocation and reliability of service. There are a few such systems in existence and they provide varying levels of coverage, data rates, and very importantly, a range of messaging costs.

The ideal situation is an AMSS that provides coverage across all longitudes and latitudes (official requirement only 78 degrees N/S), sufficiently high data rates with voice and data capability to support ATS and Airline Operation Center (AOC) needs and are secure, available at least $95 \%$ of the time, and whose Quality of Service (QOS) expressed in error rate is no more than one bit in a million, whose aircraft antenna and transceiver are affordable, and whose usage fees do not outweigh the benefits an airline would otherwise gain. Several AMSSs are reviewed below for their ability to meet the ideal situation.

$\underline{\text { Iridium }}$

Coverage - Global including polar regions due to high inclination of the orbits.

Data rates - from plane: $2.4 \mathrm{Kbps}$; to plane (Compressed data up to $10 \mathrm{Kbps}$ )

Voice/Data - Yes

Antenna/Transceiver - Low Earth Orbit, L-Band system enables small antenna system.

\section{Connexion by Boeing ${ }^{\text {SM }}$}

Coverage -Via various Ku Band geostationary satellites; no polar coverage, coverage of most oceanic areas available

Data rates - from plane: $1.5 \mathrm{Mbps}$; to plane: $10 \mathrm{~s}$ of Mbps

Voice/Data - Yes

Antenna/Transceiver - through leased, GEO Ku-band transponders, relatively large antenna system required

Inmarsat 4 (BGAN-Swift Broadband)

Coverage: L-Band global up to 70 degrees in latitude but no polar coverage

Data rates - from/to plane: $128 \mathrm{kbps}$ to $432 \mathrm{Kbps}$ )

Voice/Data - Yes

Antenna/Transceiver - Inmarsat is an L-band geostationary system. Inmarsat 4 will have a much higher EIRP compared to Inmardsat 3, allowing for smaller aircraft antenna/transceiver.

These systems have the potential for providing lower cost oceanic ATC communications and surveillance (through ADS). However, none of these three systems are as yet capable of providing these services because technical, regulatory, and safety issues must first be addressed.

Iridium has significant potential to provide low cost avionics for aircraft, as very small antennas are required. Iridium airborne terminals exist and have being tested for ATC applications in the FAA's Capstone Project[7]. Such issues as long-term reliability, message integrity, and longterm system availability require further testing. Iridium is the only candidate system that provides complete polar coverage, which is significant since the number of polar flights is increasing dramatically. The low data rate for Iridium channels could cause usage limitations. An acceptable interface of Iridium data with oceanic ATC automation systems would be required.

Connexion by Boeing ${ }^{\mathrm{SM}}$ is intended as a passenger services system, providing high rate connectivity to internet-based functions as well as live video feeds. As such, the relatively high cost of the $\mathrm{Ku}$ Band aeronautical earth station avionics may be mitigated by passenger usage fees. Connexion service is in its early stages of deployment and hence data about reliability, availability and message integrity are now being obtained. Connexion provides a broadband link using existing $\mathrm{Ku}$ band satellites, providing significant available bandwidth of potential use for non-passenger services, and is being installed on a number of aircraft flying transoceanic routes. A significant issue with the use of Connexion for ATC messaging is the safety aspect of combining passenger entertainment and safety-of-life communications on a single channel. Developing and validating acceptable security through separation of these services is one of a number of significant safety/certification issues that would need to be overcome.

Inmarsat has been providing certified ATC oceanic communications services for many years. The new generation of Inmarsat satellites, Inmarsat 4, use multiple spot-beam antennas systems providing a much higher EIRP compared to the previous generation. Hence, the potential for smaller antennas and much lower cost AES avionics, combined with higher available data rates, presents an attractive alternative. The development of Inmarsat-4 compatible earth stations is proceeding, but they are not yet intended for ATC communications.

Inmarsat is currently the only satellite system certified for oceanic ATC messaging, and the only system which uses AMSS spectrum dedicated for safety-of-life ATC communications. In order for Iridium or Connexion to be acceptable for ATC services, changes in spectrum allocation would be required. 


\section{SUMMARY}

As oceanic traffic increases, the potential for economic benefits for trans-oceanic aircraft operators resulting from improving oceanic air traffic management efficiencies grows. Currently aircraft in oceanic and other remote regions are separated by distances of $50 \mathrm{~nm}$ or greater because the lack of high quality communications and surveillance yield large uncertainties in aircraft position. Air traffic services providers controlling oceanic airspace are now implementing air traffic control automation systems which will enable significant reductions in aircraft spacing requirements as well as other advanced features. These systems can provide significant improvements in the efficiency of oceanic air traffic operations, yielding economic benefits to aircraft operators.

The air traffic control automation systems require a minimum communications capability for the oceanic aircraft fleet. The percentage of aircraft meeting the equipage requirement is growing slowly. The availability of lower cost satellite communications systems would accelerate the equipage rate and bring increased operational efficiencies and their corresponding economic benefits more rapidly. Several existing satellite communications systems are candidates for lower cost oceanic communications. However these systems require the solution of technical, regulatory and safety issues before they can be approved for oceanic ATC use.

\section{REFERENCES}

1. FAA Long Range Aerospace Forecasts Fiscal Years 2015, 2020, 2025, 2030, Federal Aviation Administration Office of Aviation Policy and Plans, June 2003.

2. Final Report of the Working Group on Oceanic and Sparse Area Communications, of the FAA REDAC Air Traffic Services Subcommittee, Paul Drouilhet, Chairman, June, 2004.

3. Federal Aviation Administration Oceanic and Offshore Services,

http://www.faa.gov/aua/oceanicatc/index.cfm?content= dots.

4. Operator Benefits of Future Air Navigation System, Boeing Aero Magazine, Vol. 1, No. 2, Spring 1998.

5. National Airspace System Concept of Operations and Vision for the Future of Aviation, RTCA, Inc., December 2002.
6. D. Morse, Next Generation FANS over BGAN, $4^{\text {th }}$ Integrated CNS Conference and Workshop, April, 2004.

7. FAA Capstone Project http://www.alaska.faa.gov/capstone/news/0402/0402.ht $\mathrm{m}$

\section{BIOGRAPHIES}

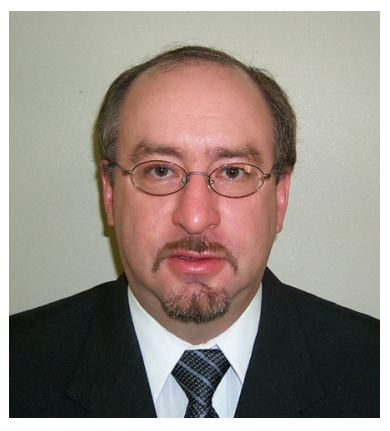

Robert J. Kerczewski has been involved with research and development of satellite communications systems and applications since for the Analex Corporation (19821986) and NASA (1986present). He holds a BEE degree from Cleveland State University (1982) and an MSEE degree from Case Western Reserve University (1987). He is currently the Project Manager for the NASA's Advanced CNS Architectures and System Technologies (ACAST) Project.

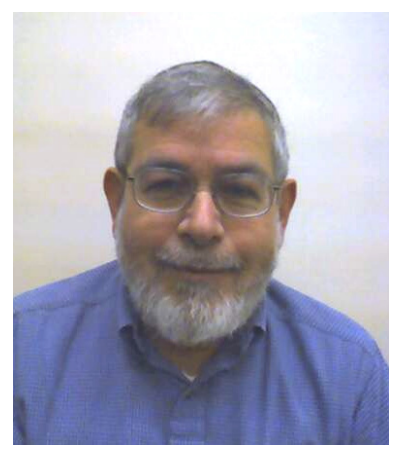

Israel Greenfeld is a senior communications systems analyst at the NASA Glenn Research Center with experience in space and aeronautical communications. Prior work involved orbital mechanics and launch vehicle system analysis. Mr. Greenfeld has a BS Degree in Physics.

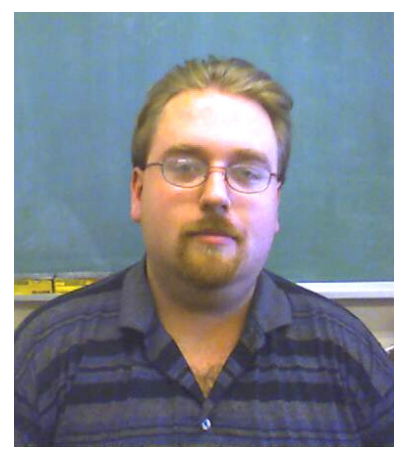

Bryan W. Welch has been involved with systems level research and analysis of satellite communications systems and applications for NASA since 2002. He holds a BSEE degree from Cleveland State University (2002) and is currently working on his MSEE degree from Cleveland State University. $\mathrm{He}$ is currently a communications systems analyst for the Communication System Integration Branch. 